\title{
CHRYSOMELID BEETLE MOVEMENTS IN RELATION TO HOST-PLANT SIZE AND SURROUNDING NON-HOST VEGETATION ${ }^{1}$
}

\author{
W. S. LAWRENCE AND C. E. BACH \\ Department of Biology, University of Michigan, Ann Arbor, Michigan 48109-1048 USA
}

\begin{abstract}
The effects of host-plant size and surrounding non-host vegetation on herbivore population dynamics were examined for two species of cucurbit-feeding chrysomelid beetles. Population densities were assessed in an experimental garden where host-plant patches were (1) either fertilized or unfertilized and (2) surrounded either by large nonhost plants (tomato) or by mowed grasses. In order to assess the role of movement patterns in influencing beetle population densities, a second related experiment examined the flight behavior of individual beetles.

Both Acalymma vittatum (striped cucumber beetle) and Diabrotica undecimpunctata howardi (spotted cucumber beetle or southern corn rootworm) were more abundant in patches without tomato edges. D. undecimpunctata howardi was also more abundant in fertilized than in unfertilized patches, while $A$. vittatum was not affected by fertilization. When host-plant size was controlled for $A$. vittatum was still affected by the presence of tomato edges. In contrast, $D$. undecimpunctata howardi was no longer affected by tomato edges, but remained more abundant in fertilized patches. Thus it appears that tomato edges can have two different and important effects on insect herbivore abundance: (1) direct effects (e.g., as in $A$. vittatum), or (2) indirect effects resulting from changes in host-plant size or quality (e.g., as in $D$. undecimpunctata howardi).

Mark-recapture and movement behavior experiments indicated that the two beetle species exhibited different movement patterns. A. vittatum colonized patches without tomato edges significantly more frequently than other patches, but only $24.3 \%$ of subsequent recaptures revealed interpatch movement, and beetles moving between patches showed no selectivity with respect to patch type. In contrast, $D$. undecimpunctata howardi showed both initial selectivity and subsequent movement in response to differences in plant size and quality caused by the fertilization and edge treatments. $D$. undecimpunctata howardi colonized patches without tomato edges and with fertilization significantly more frequently than other patches. Furthermore, $38.7 \%$ of subsequent recaptures revealed interpatch movement, and moving beetles preferentially chose patches without tomato edges. Abundances of $A$. vittatum seemed to be largely determined by patch choice during initial colonization while for $D$. undecimpunctata howardi there was considerable post-colonization movement between patches that influenced beetle distribution.

Results on individual flight behavior revealed that $D$. undecimpunctata howardi was nearly seven times as likely to initiate flight as was $A$. vittatum. For $D$. undecimpunctata howardi flights were more likely to lead to emigration from patches that were unfertilized but surrounded by tomato plants than from all other treatments. Taken together, these differences between the two species in movement behavior may help explain observed distribution patterns. The results are consistent with previous studies examining patch size and diversity effects on herbivorous insects.
\end{abstract}

Key words: Acalymma; Cucurbitaceae; Diabrotica; herbivore movement patterns; herbivore-plant interactions; host-plant patch edges; host-plant quality; host-plant size; insect herbivory; insect population dynamics; neighboring plants; plant diversity.

\section{INTRODUCTION}

The question of how the spatial dispersion of plant resources influences herbivore populations is of critical importance to our understanding of insect-plant interactions. Since there is a high degree of patchiness in plant communities, herbivores are continually faced with the problem of how to respond to the distribution

\footnotetext{
'Manuscript received 16 September 1988; revised 1 February 1989; accepted 10 February 1989.
}

and quality of their host-plant resources. In addition, for mobile females with sedentary offspring, host-plant patch selection and residence can influence both individual fitness and subsequent population size and distribution (Rausher 1979, 1980).

Although recent work has reported a bewildering array of responses to host-plant patch properties by different insect herbivores (see reviews by Kareiva 1983 and Stanton 1983), the apparent de facto conclusion that there are no general patterns may be premature. 
Many previous studies have suffered from two problems. First, as pointed out by Kareiva (1983), Bach $(1988 a, b)$, and others, many variables of host-plant patches are often confounded. Second, comparative studies of several insect herbivores in the same system are rare. This precludes an incorporation of differences in insect herbivore movement behavior in the formulation of any general theory. Many studies have shown that movement behavior strongly influences the size of local populations of herbivores (Turchin 1987, Lawrence 1988). Here we attempt to examine how nonhost-plant patch edges and the often-confounding variable of host-plant size influence both the movement behavior and subsequent distribution of two closely related insect herbivores.

In a recent study of the mechanisms underlying the effects of patch size on herbivore abundance, Bach $(1988 b)$ found that for any given size patch (particularly small ones) Acalymma vittatum densities were affected by non-host neighbors surrounding host-plant patches. The surrounding vegetation had both positive effects on densities resulting from reduced emigration rates, and negative effects resulting from a decrease in host-plant size. In addition, a closely related species, Diabrotica undecimpunctata howardi, also responded to the presence of non-host-plant patch edges.

These results led us to question how host-plant size and non-host neighbors interact to determine the densities of these two chrysomelid species in the field. Specifically, the experiments reported here were designed to test the relative importance of (1) host-plant size or correlated plant properties, and (2) non-hostplant patch edges, on the population densities of these two herbivorous insects. We manipulated host-plant size by the addition of fertilizer and varied the surrounding plant community by planting non-host neighbors around the host-plant patches.

We were particularly interested in determining how differences in movement behavior of the two species influence observed differences in distribution. Markrecapture work and experiments testing beetle flight behavior were used to compare for the two species how (1) host-plant size and non-host-plant patch edges influenced immigration and emigration rates, and (2) what aspects of flight behavior might account for differences in observed immigration and emigration patterns.

\section{Methods}

The system. - The two herbivores we chose to study were chrysomelid beetles that feed on plants of the family Cucurbitaceae. Acalymma vittatum (striped cucumber beetle) is a specialist on cucurbits as both an adult and larva (Houser and Balduf 1925), whereas Diabrotica undecimpunctata howardi (spotted cucumber beetle or southern corn rootworm) is a generalist on members of the families Cucurbitaceae, Graminae, and Leguminoseae (Campbell and Emery 1967). Both species overwinter as adults, but $A$. vittatum is bivol- tine, whereas D. undecimpunctata howardi is univoltine. Throughout the remainder of this paper we will refer to this latter species as $D$. undecimpunctata. Details of the response of these species to plant diversity, plant density, and patch size can be found in Bach (1980a, b, 1988a, b).

Experimental plots. - The experiments were conducted at the Matthaei Botanical Gardens of the University of Michigan (Ann Arbor, Michigan) during the summer of 1987. The experimental design was a $2 \times$ 2 factorial design, with treatments being arranged in a hexagonal pattern so that each patch was surrounded at equal distances by three patches, one each of the other three treatments (Fig. 1). We used 36 patches in all, each patch type being replicated 8 or 10 times. Our treatments were either fertilized or unfertilized and either with or without non-host-plant patch edges.

Patches were located in an agricultural field. Each patch contained four squash plants and was $6.2 \mathrm{~m}^{2}$. The plots were plowed in April and disked early in May. Squash seeds (Buttercup, Cucurbita maxima, bush variety) were planted during the $3 \mathrm{rd}$ wk of May, at 0.5 -m intervals with $0.5 \mathrm{~m}$ between rows. Fertilized treatments received $\approx 6.5 \mathrm{~g}$ of $14-14-14$ (N:P:K) fertilizer worked into the soil below the seed, and $\approx 6.5$ $\mathrm{g}$ of the slow-release fertilizer Osmocote on 1 July. Tomato plants (Lycopersicon esculentum, variety Big Boy) were used as the non-host neighbor and were also planted at $0.5-\mathrm{m}$ intervals, thus giving 12 tomato plants per patch. The tomatoes were started in the greenhouse and fertilized with 14-14-14 N:P:K fertilizer when planted during the 3rd wk of May. All patches (including a 0.5 -meter border outside of the tomato plants in tomato treatments and a $1-\mathrm{m}$ border outside of the squash plants in treatments without tomatoes) were mulched with newspaper and hay during the 4th wk of May. An unusually late frost on 8 June killed some of the squash and tomato seedlings. These were replaced on 16 June with seedlings previously germinated in the greenhouse. No differences were subsequently detected between patches that had some plants replaced and those that did not. The area between patches was mowed three times during the course of the experiment.

Sampling methods. - Starting on 17 June each patch was censused on Monday and Wednesday of each week. On each Monday the number of beetles on each plant in each patch was recorded. The locations and number of all marked beetles were also recorded, and all unmarked beetles were returned to the laboratory, individually marked using Testors brand enamel paint and returned to the plant on which they had been captured. On Wednesday all plots were again censused, and both the number of beetles on each plant and the locations of all marked beetles were recorded.

We used mark-recapture methods to examine patterns of colonization, and subsequent emigration, immigration, and residency. We defined colonization as 
occurring when unmarked beetles first enter the system, are captured, and marked. We assumed that all unmarked beetles are colonists (the field was not planted in squash for the prior two years and no first-generation offspring emerged by the end of the study) and that beetles do not move between patches prior to marking. Emigration, immigration, and residency were assessed by determining the locations of marked beetles on subsequent sampling dates. We measured residency as the percentage of beetles released in a patch that were subsequently recaptured in the same patch.

During the course of the study $351 \mathrm{~A}$. vittatum and $228 \mathrm{D}$. undecimpunctata were individually marked. For A. vittatum $39.6 \%$ of the marked beetles were recaptured, and of those $36.7 \%$ had lost one of their two identifying marks. For $D$. undecimpunctata $32.4 \%$ of marked beetles were recaptured, $19.4 \%$ having lost one of their two marks. Assuming a constant probability of mark loss, 13.4 and $3.7 \%$ of marked $A$. vittatum and D. undecimpunctata can be estimated to have lost both marks. Some of the individuals with two lost marks may have been subsequently marked again and erroneously identified as colonists. The number of these errors can be estimated assuming that individuals that have lost two marks are recaptured at the same frequency as recaptured individuals that have not lost their marks. Using this approach we estimate that only $19 \mathrm{~A}$. vittatum and $3 \mathrm{D}$. undecimpunctata may have been erroneously considered colonists.

Squash plant size was monitored by counting the number of leaves with $>2.5 \mathrm{~cm}$ width on each plant on 30 June, 13 July, and 5 August. Leaf number is closely correlated with plant biomass (Bach 1988a).

Flight-behavior experiments. - To examine the flight behavior of each species of beetle, a separate experiment was conducted in an adjacent field. Four squash patches, measuring $5 \mathrm{~m}$ on a size were planted during the 3rd wk of May 1987. As in the previous experiments, plants were spaced $0.5-\mathrm{m}$ apart, mulched, and subjected to one of four treatments: fertilized and without a border of tomato, fertilized and with a border of tomato, unfertilized and without a border of tomato, and unfertilized and with a border of tomato. As in the previously described plantings, all tomato plants were fertilized. To determine the location at which flights began and ended each patch was located at the center of a $25 \times 25 \mathrm{~m}$ area marked off in a 1 -m grid. Each of the 625 points on the grid was conspicuously marked with a $45-\mathrm{cm}$ stake bearing the coordinates of that point. A more complete replication scheme was not possible due to the considerable effort necessary to set up each patch.

During the afternoons of $8 \mathrm{~d}, 27$ and 29 July and 3, $5,8,12,13$, and 17 August, individuals of $A$. vittatum, D. undecimpunctata, and other herbivores (primarily, Diabrotica virgifera, the western corn rootworm) were removed from the patches. The following mornings, at $0600,50 \mathrm{~A}$. vittatum and $50 \mathrm{D}$. undecimpunctata were

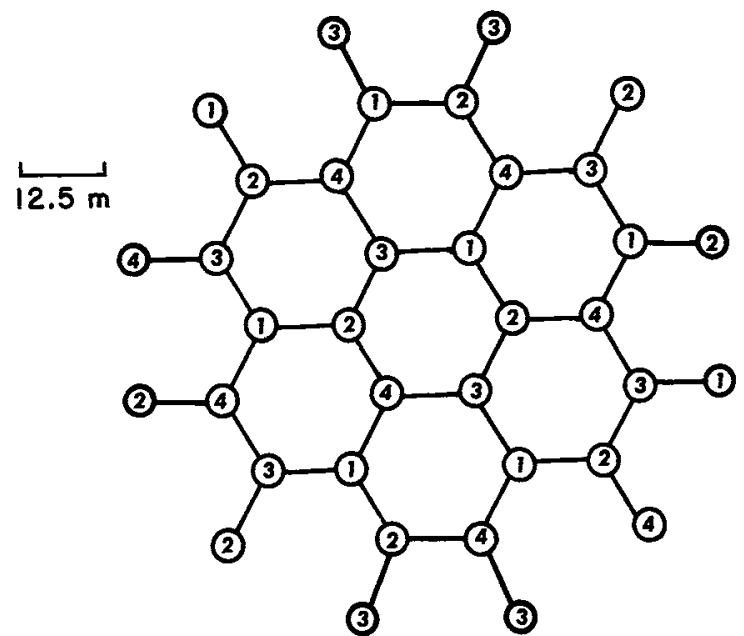

Fig. 1. Spatial arrangement of the 36 experimental patches used to examine beetle population densities, residency, and movement. The four treatments are: squash without tomato edges or fertilizer (1), squash without tomato edges but with fertilizer (2), squash with tomato edges but without fertilizer (3), and squash with both tomato edges and fertilizer (4).

released into two of the four patches. Releases in each patch were replicated four times.

Following the release of the 50 test beetles into the patches, at 0800 an observer began continual monitoring of each patch. Three observers were rotated between the patches at 20 -min intervals. For each beetle that moved $>0.5 \mathrm{~m}$ (i.e., between grid squares) the observers recorded, onto tape, the time, species, starting location, initial plant species occupied, ending location, and plant species on which the beetle landed. These observations provided a useful estimate under natural conditions of differences between the species in flight frequency, flight length, and patterns of emigration from host plant patches differing in their characteristics.

Initial trials had shown that most flights occurred during the morning, so observations were terminated at 1200 . We attempted to conduct all experiments on sunny, clear, and calm days. Unfortunately, poor weather and other factors forced us to discard data from two replicates of the fertilized tomato-edge treatment and one replicate of the unfertilized tomato treatment.

Squash plant size was measured in these four patches on 18 August. In addition to the number of leaves, plant height was also measured.

Data analysis. - Data were analyzed by computer using Systat (Wilkinson 1988). Because plants within patches and the same patches on Monday and Wednesday are not independent replicates, analyses were performed on average values of the four plants and the two sampling dates for the censuses in each patch each week. In addition, since it can reasonably be argued that successive weekly beetle counts are not indepen- 
TABLE 1. Results from repeated measures 2-way ANOVAs of beetle numbers per plant throughout the season. Sums of squares, $F$ values, degrees of freedom, and $P$ values (NS $=$ not significant) are presented for effects of tomato edge treatment, fertilization, time, and interactions between these factors.

\begin{tabular}{|c|c|c|c|c|c|c|c|c|}
\hline \multirow[b]{2}{*}{ Source of variation } & \multicolumn{4}{|c|}{ Acalymma vittatum } & \multicolumn{4}{|c|}{ Diabrotica undecimpunctata howardi } \\
\hline & ss & $F$ & df & $P$ & ss & $F$ & df & $P$ \\
\hline $\begin{array}{l}\text { Tomato } \\
\text { Error }\end{array}$ & $\begin{array}{l}17.13 \\
42.06\end{array}$ & 13.03 & $\begin{array}{r}1 \\
32\end{array}$ & $<.001$ & $\begin{array}{l}7.76 \\
6.77\end{array}$ & 36.68 & $\begin{array}{r}1 \\
32\end{array}$ & $<.001$ \\
\hline $\begin{array}{l}\text { Fertilizer } \\
\text { Error }\end{array}$ & $\begin{array}{r}2.31 \\
42.06\end{array}$ & 1.75 & $\begin{array}{r}1 \\
32\end{array}$ & NS & $\begin{array}{l}1.39 \\
6.77\end{array}$ & 6.55 & $\begin{array}{r}1 \\
32\end{array}$ & $<.05$ \\
\hline $\begin{array}{l}\text { Time } \\
\text { Error }\end{array}$ & $\begin{array}{r}8.37 \\
67.79\end{array}$ & 3.95 & $\begin{array}{r}5 \\
160\end{array}$ & $<.01$ & $\begin{array}{r}2.59 \\
17.81\end{array}$ & 4.66 & $\begin{array}{r}4 \\
128\end{array}$ & $<.01$ \\
\hline $\begin{array}{l}\text { Tomato } \times \text { Fertilizer } \\
\text { Error }\end{array}$ & $\begin{array}{r}0.40 \\
42.06\end{array}$ & 0.30 & $\begin{array}{r}1 \\
32\end{array}$ & NS & $\begin{array}{l}0.16 \\
6.77\end{array}$ & 0.76 & $\begin{array}{r}1 \\
32\end{array}$ & NS \\
\hline $\begin{array}{l}\text { Tomato } \times \text { Time } \\
\text { Error }\end{array}$ & $\begin{array}{r}5.52 \\
67.79\end{array}$ & 2.42 & $\begin{array}{r}5 \\
160\end{array}$ & $<.05$ & $\begin{array}{r}0.36 \\
17.81\end{array}$ & 0.64 & $\begin{array}{r}4 \\
128\end{array}$ & NS \\
\hline $\begin{array}{l}\text { Fertilizer } \times \text { Time } \\
\text { Error }\end{array}$ & $\begin{array}{r}2.64 \\
67.79\end{array}$ & 1.25 & $\begin{array}{r}5 \\
160\end{array}$ & NS & $\begin{array}{r}1.24 \\
17.81\end{array}$ & 2.23 & $\begin{array}{r}4 \\
128\end{array}$ & NS \\
\hline
\end{tabular}

differences and control for possible differences between plants. In the 36-patch population-density experiment the presence of tomato plants significantly decreased the number of leaves per squash plant $(F=46.96, \mathrm{df}$ $=1,32, P<.001 ;$ Fig. 3). Fertilization significantly increased the number of leaves per plant $(F=4.79$, df $=1,32, P<.05$; Fig. 3), and the number of leaves per plant also increased during the course of the experiment $(F=32.18$, df $=2,64, P<.001)$. There was a significant interaction between time and tomato edge $(F=11.02, \mathrm{df}=2,64, P<.001)$, with greater differences as the season progressed. No other 2- or 3-way interactions were significant. Thus the treatments did have the desired effects on host-plant size.

To control for these differences in host-plant size as a function of edge treatment, it is also necessary to examine beetle abundances on a per-leaf basis (Fig. 4A). There were significantly more $A$. vittatum per leaf in patches without tomato edges than in patches with tomato edges (Table 2). Since even when plant size is controlled for, $A$. vittatum was more abundant in patches that lack tomato edge plants, $A$. vittatum densities were not determined by an effect of tomato plants on hostplant size or a correlated plant attribute, but by the tomato plants themselves. $A$. vittatum abundance per leaf was not significantly affected by fertilization, although there is a strong trend suggesting that beetles may be more abundant in fertilized patches (Table 2). There was, however, a significant effect of time on beetle abundance (Table 2), densities peaking on 28 July. There were no significant 2-or 3-way interactions.

For D. undecimpunctata a different pattern emerged (Fig. 4B). Tomato edges did not significantly affect beetle abundances per leaf (Table 2). Changes in host-plant size, or some aspect of plant quality which is correlated with plant size, accounted for the observed differences in $D$. undecimpunctata abundance per plant. These differences in plant size or quality were, however, caused by the presence of tomato plants.

Densities of $D$. undecimpunctata per leaf were still significantly higher in fertilized treatments than in unfertilized treatments (Table 2), indicating an effect of fertilization over and above the effect on host-plant size. Time had a significant effect on beetle abundance, with densities per leaf peaking on 28 July. No 2- or 3-way interactions were significant.

\section{Beetle movement}

We used two approaches to address the question of the role of movement in determining distribution and abundance of the two beetle species. First, we examined rates of colonization, residency, and interpatch movement for both species in the 36-patch populationdensity experiment (see Methods: Sampling Methods). Second, we examined the flight behavior of individuals of the two species in and around the four larger experimental host-plant patches. Specifically, we examined flight frequency, distance flown, and starting and

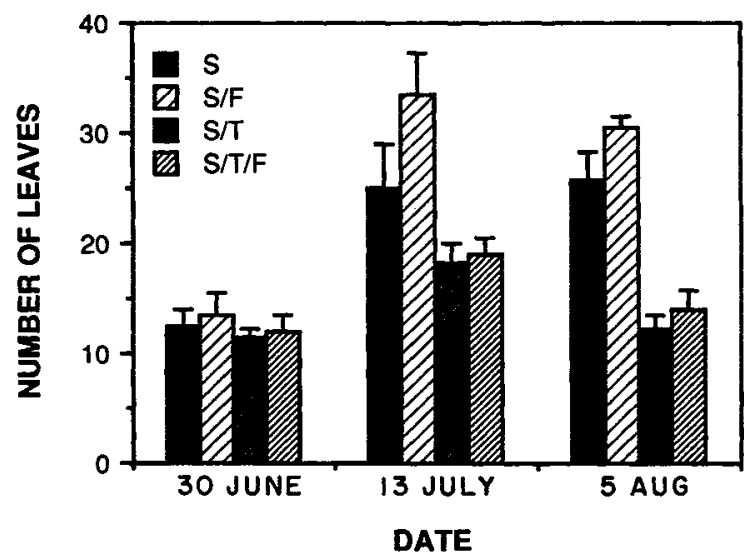

FIG. 3. The number of leaves per plant on three sampling dates (means $+1 \mathrm{SE}$ ) are shown for the experimental squash patches used to examine beetle densities and movement. The patches were either without tomato edges or fertilizer (S), without tomato edges, but fertilized (S/F), with tomato edges but without fertilizer $(\mathrm{S} / \mathrm{T})$, or with tomato edges and fertilizer (S/T/F). 

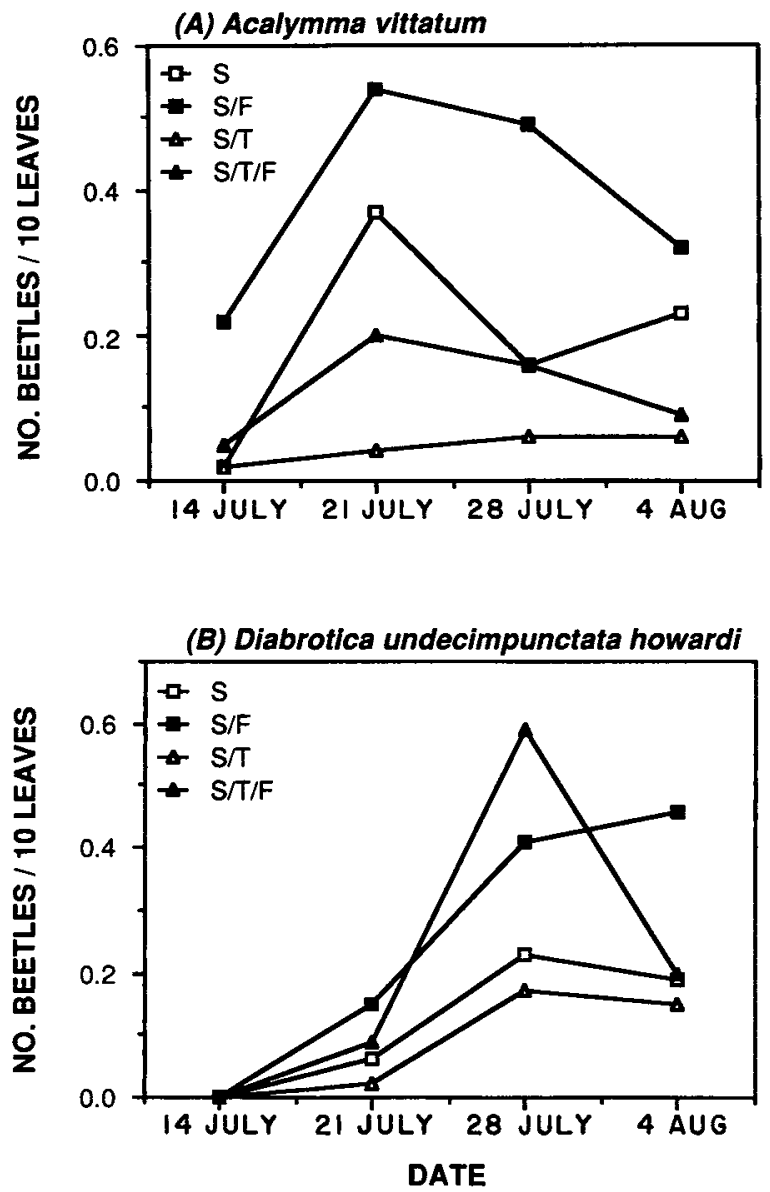

Fig. 4. Numbers of beetles per 10 leaves of Acalymma vittatum (A) and Diabrotica undecimpunctata howardi (B). Densities are shown separately for the four treatments: squash without tomato edges or fertilizer $(S, \square)$, squash without tomato edges but with fertilizer $(\mathrm{S} / \mathrm{F}, \mathbf{\square})$, squash with tomato edges but without fertilizer $(\mathrm{S} / \mathrm{T}, \Delta)$ and squash with both tomato edges and fertilizer $(\mathrm{S} / \mathrm{T} / \mathrm{F}, \boldsymbol{\Delta})$. Dates are the average of the two sampling dates each week ending locations of all moving individuals. By comparing these parameters of movement for the two species it was possible to evaluate whether species differences in movement behavior help explain the observed species differences in abundance.

Colonization.-Densities of colonizing beetles were significantly affected by tomato edges for both $A$. vittatum $(F=7.9$, df $=1,32, P<.01)$ and $D$. undecimpunctata $(F=16.6, \mathrm{df}=1,32, P<.0001)$ (Fig. 5), with greater densities in patches with no tomato edges. Fertilization did not significantly affect densities of either colonizing $A$. vittatum $(F=1.7, \mathrm{df}=1,32, P>.05)$ or D. undecimpunctata $(F=2.1$, df $=1,32, P>.05)$.

To examine the relative importance of initial colonization (as opposed to subsequent immigration and emigration) in influencing population densities, we examined the proportion of total captures (i.e., both marked and unmarked beetles) that were colonists for each species. Colonists comprised a remarkably constant proportion of the $A$. vittatum observed in each treatment (Table 3$)$. Neither edge treatment $(F=0.03$, $\mathrm{df}=1,30, P>.05)$ nor fertilization $(F=2.17, \mathrm{df}=$ $1,30, P>.05$ ) affected the proportion of captured $A$. vittatum in each patch that were colonists.

Colonists did not represent a constant proportion of recaptures of $D$. undecimpunctata in the different treatments (Table 3$)$. Both tomato edges $(F=4.78$, df $=$ $1,30, P<.05)$ and fertilization $(F=4.36$, df $=1,30$, $P=.05)$ affected the relative abundance of colonists. D. undecimpunctata colonists represented a higher proportion of captures in patches with tomato edges and in patches without fertilization. Thus, beetles of this species either have lower emigration rates from or higher immigration rates to patches without fertilizer or with tomatoes, as compared to patches with fertilizer or without tomato edges.

Residency.-Residency in each patch type is presented for $A$. vittatum and $D$. undecimpunctata (Table 4). Summed across all treatments, $14.0 \%$ of marked $A$. vittatum and $16.7 \%$ of marked $D$. undecimpunctata

TABLE 2. Results from repeated measure 2-way ANOVAs of beetle numbers per 10 leaves throughout the season. Sums of squares, $F$ values, degrees of freedom and $P$ values (Ns $=$ not significant) are presented for effects of tomato edge treatment, fertilization, time, and interactions between these factors.

\begin{tabular}{|c|c|c|c|c|c|c|c|c|}
\hline \multirow[b]{2}{*}{ Source of variation } & \multicolumn{4}{|c|}{ Acalymma vittatum } & \multicolumn{4}{|c|}{ Diabrotica undecimpunctata howardi } \\
\hline & ss & $F$ & $\mathrm{df}$ & $P$ & ss & $F$ & $\mathrm{df}$ & $P$ \\
\hline $\begin{array}{l}\text { Tomato } \\
\text { Error }\end{array}$ & $\begin{array}{l}0.018 \\
0.060\end{array}$ & 9.16 & $\begin{array}{r}1 \\
32\end{array}$ & $<.01$ & $\begin{array}{l}0.003 \\
0.022\end{array}$ & 0.58 & $\begin{array}{r}1 \\
32\end{array}$ & $<.05$ \\
\hline $\begin{array}{l}\text { Fertilizer } \\
\text { Error }\end{array}$ & $\begin{array}{l}0.003 \\
42.06\end{array}$ & 3.97 & $\begin{array}{r}1 \\
32\end{array}$ & NS & $\begin{array}{l}0.005 \\
0.022\end{array}$ & 8.25 & $\begin{array}{r}1 \\
32\end{array}$ & $<.01$ \\
\hline $\begin{array}{l}\text { Time } \\
\text { Error }\end{array}$ & $\begin{array}{l}0.013 \\
0.134\end{array}$ & 4.11 & $\begin{array}{r}5 \\
160\end{array}$ & $<.05$ & $\begin{array}{l}0.016 \\
0.067\end{array}$ & 11.17 & $\begin{array}{r}4 \\
128\end{array}$ & $<.001$ \\
\hline $\begin{array}{l}\text { Tomato } \times \text { Fertilizer } \\
\text { Error }\end{array}$ & $\begin{array}{l}0.001 \\
0.060\end{array}$ & 0.79 & $\begin{array}{r}1 \\
32\end{array}$ & NS & $\begin{array}{l}0.000 \\
0.022\end{array}$ & 0.00 & $\begin{array}{r}1 \\
32\end{array}$ & NS \\
\hline $\begin{array}{l}\text { Tomato } \times \text { Time } \\
\text { Error }\end{array}$ & $\begin{array}{l}0.005 \\
0.134\end{array}$ & 1.38 & $\begin{array}{r}5 \\
160\end{array}$ & NS & $\begin{array}{l}0.003 \\
0.067\end{array}$ & 1.63 & $\begin{array}{r}4 \\
128\end{array}$ & NS \\
\hline $\begin{array}{l}\text { Fertilizer } \times \text { Time } \\
\text { Error }\end{array}$ & $\begin{array}{l}0.005 \\
0.134\end{array}$ & 0.60 & $\begin{array}{r}5 \\
160\end{array}$ & NS & $\begin{array}{l}0.006 \\
0.067\end{array}$ & 1.85 & $\begin{array}{r}4 \\
128\end{array}$ & $<.01$ \\
\hline
\end{tabular}



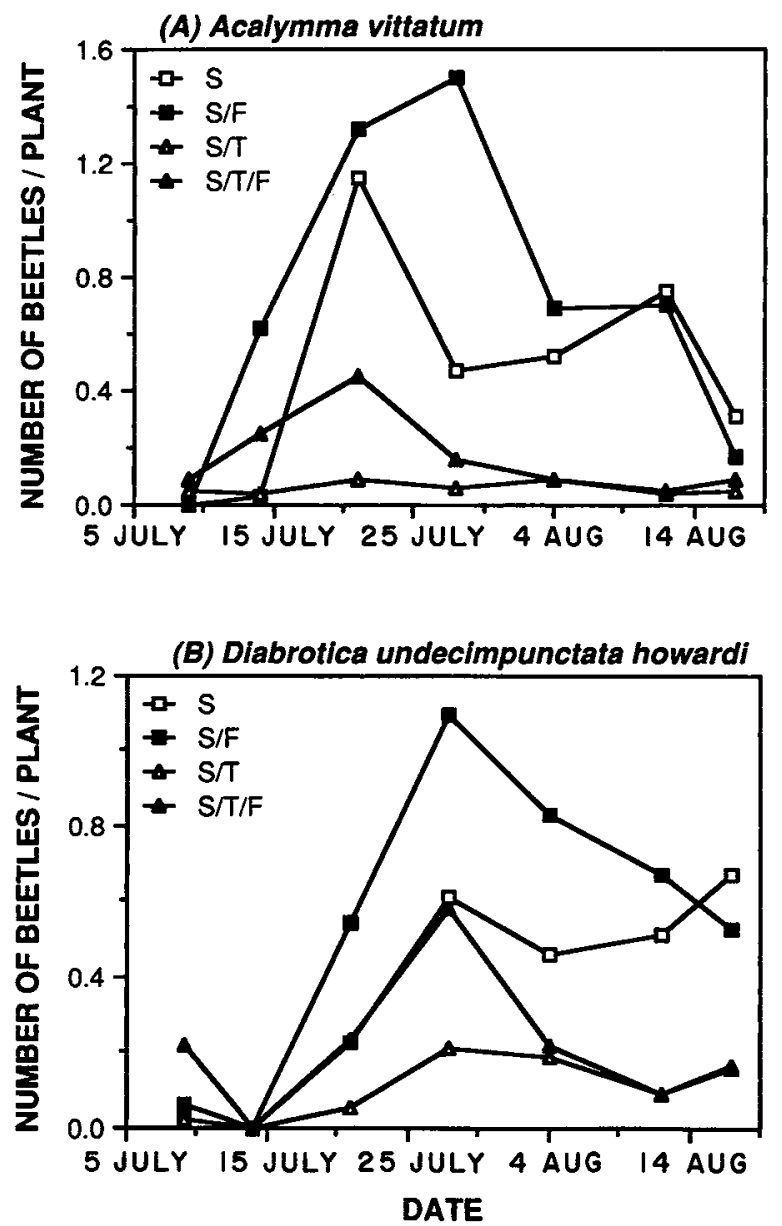

Fig. 2. Numbers of beetles per plant of Acalymma vittatum (A) and Diabrotica undecimpunctata howardi (B). Densities are shown separately for the four treatments: squash without tomato edges or fertilizer $(S, \square)$, squash without tomato edges but with fertilizer $(S / F, \square)$, squash with tomato edges but without fertilizer $(\mathrm{S} / \mathrm{T}, \Delta)$ and squash with both tomato edges and fertilizer $(\mathrm{S} / \mathrm{T} / \mathrm{F}, \Delta)$. Dates are the average of the two sampling dates each week.

dent (although beetle mobility is relatively high and beetles remain in the experimental plots for a relatively few days), we analyzed the data using a repeated measures 2-way ANOVA to examine the effects on beetle abundance of tomato edges, fertilization, and time, as well as the interactions between these factors. Plant characteristics were analyzed in a similar manner.

To control for differences in host-plant size when examining the effects of tomato edges on beetle abundance, beetle abundances were analyzed both on a perplant and a per-leaf basis. The number of leaves was used as the measure of plant size, since it is significantly correlated with plant biomass (Bach 1988a). For census dates on which leaf number was not counted, the value from the closest date was used. Between 5 August and 12 August, however, many plants lost all or many leaves due to damage caused by the squash stem borer, Melittia cucurbitae. Since leaf counts taken on 5 August were therefore not a good measure of plant size on 12 August, beetle abundances on a per-leaf basis were not analyzed after 4 August.

The 24 interior patches in the experimental array possessed complete sets of three neighboring patches, although the 12 peripheral patches contained only a single neighboring patch. Accordingly, we initially analyzed interior and peripheral patches separately. Since we found that beetles of both species did not respond differently to interior and peripheral patches, these groups were pooled for the analysis presented here.

Data on individual flights were examined using 2-way ANOVA to test for effects of tomato edges, fertilization, and an interaction between the two factors. Differences between flight behavior of the two beetle species were compared with Student's $t$ tests and, for frequency data, with log-linear models and $\chi^{2}$ tests (Sokal and Rohlf 1981). Although preferable, log-linear models were used only in analyses of the flight behavior experiments. They were not used in the population-level experiment where expected values of emigrants and immigrants needed to be weighted by patch frequency. In these cases $\chi^{2}$ tests were used. All percentages were arcsine transformed prior to analysis. Where means are presented, standard errors are also given.

\section{RESULTS \\ Patterns of beetle abundance}

The mean numbers of Acalymma vittatum per plant in the four treatments over the season are presented in Fig. 2A. Beetles were significantly more abundant per plant in patches without tomato edges than in patches with tomato edges (Table 1). Fertilizer did not have a significant effect on the number of beetles per plant. The significant effect of time (Table 1) indicates that beetle abundances changed during the season, and the significant time $\times$ tomato-edge interaction reflects the similar number of beetles in treatments with and without tomatoes at the beginning and end of the season (Fig. 2A). There were no other significant 2- or 3-way interactions (Table 1).

The number of Diabrotica undecimpunctata per plant was also affected by the presence or absence of tomato edges (Fig. 2B). Beetles were significantly more abundant in patches without tomato edges than in patches with tomato edges (Table 1). In addition, beetle densities were greater in patches with fertilized plants than in patches with unfertilized plants (Table 1). Time had a significant effect on beetle abundance, densities per plant being highest on 28 July (Fig. 2B). No 2- or 3-way interactions were significant, although there is a suggestion that as the season progressed fertilization became progressively less important in determining $D$. undecimpunctata abundance (Table 1).

The treatments were designed, however, to produce differences in the host plants in each type of patch. It is therefore necessary to examine the squash plants for 


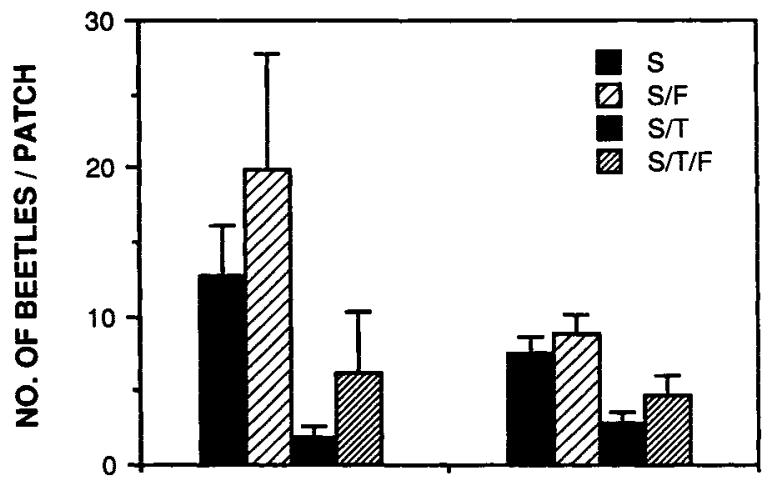

A. vittatum
D. U. howardi SPECIES

Fig. 5. Densities of colonizing $A$. vittatum and $D$. undecimpunctata howardi. Means and standard errors are presented for the total number of beetles colonizing each patch. Treatment key as in Fig. 3.

were recovered in the patch in which they were last located, and these values do not differ statistically $\left(\chi^{2}\right.$ $=0.55, \mathrm{df}=1, P>.05)$. There was no significant effect of treatment on the likelihood of being recaptured in the same patch for $A$. vittatum $\left(\chi^{2}=3.98, \mathrm{df}=3, P>\right.$ $.05)$. Neither the presence of tomato edge $\left(\chi^{2}=0.03\right.$, $\mathrm{df}=1, P>.05)$ nor fertilization $\left(\chi^{2}=3.44, \mathrm{df}=1, P\right.$ $>.05)$ significantly affected the proportion of $A$. vittatum remaining in the patch in which they were last captured.

In contrast, treatment significantly affected $D . u n$ decimpunctata residency (Table $4, \chi^{2}=10.22, \mathrm{df}=3$, $P<.025)$. The lack of tomato edges $\left(\chi^{2}=5.97, \mathrm{df}=\right.$ $1, P<.05)$ and the presence of fertilization $\left(\chi^{2}=9.56\right.$, $\mathrm{df}=1, P<.01)$ both increased the proportion of $D$. undecimpunctata remaining in the patch in which they were last captured. These differences in residency were not caused by differences in the number of days between recaptures. Although the number of days between recaptures within the same patch was greater for D. undecimpunctata $(3.71 \pm 0.43 \mathrm{~d})$ than for $A$. vittatum $(2.26 \pm 0.16 \mathrm{~d})(t=3.51, \mathrm{df}=85, P<.001)$, treatment did not influence the number of days between recaptures for either species.

Interpatch movement. - The two species differed in the frequency with which they moved between patches. For $A$. vittatum $24.3 \%$ of all recaptured beetles moved between patches, whereas $38.7 \%$ of recaptured individuals of $D$. undecimpunctata had moved between patches. A significantly higher proportion of recaptured D. undecimpunctata moved between patches than did A. vittatum $\left(\chi^{2}=3.88, \mathrm{df}=1, P<.05\right)$.

The species also differed in the distances moved by individuals moving between patches (Fig. 6). The mean distance moved between patches was significantly greater for A. vittatum $(54.27 \pm 8.64 \mathrm{~m})$ than for $D$. undecimpunctata $(28.58 \pm 4.53 \mathrm{~m})(t=2.34, \mathrm{df}=37$, $P<.05)$. Only $16.7 \%$ of $D$. undecimpunctata moved

TABLE 3. Percentage of all observed beetles of each species that were colonists in squash (S), fertilized squash (S/F), squash surrounded by tomato $(\mathrm{S} / \mathrm{T})$, and fertilized squash surrounded by tomato $(\mathrm{S} / \mathrm{T} / \mathrm{F})$ patches.

\begin{tabular}{|c|c|c|}
\hline \multirow[b]{2}{*}{ Treatment } & \multicolumn{2}{|c|}{ Percent colonists } \\
\hline & A. vittatum & $\begin{array}{c}D . \\
\text { undecimpunctata } \\
\text { howardi }\end{array}$ \\
\hline $\mathrm{S}$ & 87.1 & 82.4 \\
\hline $\mathrm{S} / \mathrm{F}$ & 82.6 & 64.5 \\
\hline $\mathrm{S} / \mathrm{T}$ & 90.5 & 90.3 \\
\hline $\mathrm{S} / \mathrm{T} / \mathrm{F}$ & 85.1 & 78.0 \\
\hline
\end{tabular}

$>50 \mathrm{~m}$ while $53.3 \%$ of $A$. vittatum moved $>50 \mathrm{~m}$. These differences did not result from differences in the number of days between recaptures for the two species (A. vittatum: $4.53 \pm 0.91$ d vs. D. undecimpunctata: $5.33 \pm 1.07 \mathrm{~d}, t=0.52, \mathrm{df}=37, P>.05$ ).

Marked beetles of both species that moved between patches did not preferentially move to either fertilized or unfertilized patches. $D$. undecimpunctata moved to patches without tomato edges significantly more frequently than to patches with tomato edges $\left(17 / 24, \chi^{2}\right.$ $=4.17, \mathrm{df}=2, P<.05$ ). For $A$. vittatum there was no significant effect of tomato edge treatment on numbers of individuals moving to patches $\left(11 / 15, \chi^{2}=2.83\right.$, df $=2, P>.05$ ), though the trend was similar.

Under some circumstances the patch type that an individual previously occupied influenced the patch type to which it moved. The presence or absence of tomatoes at the previous patch of occupancy significantly influenced $D$. undecimpunctata movement $\left(\chi^{2}\right.$ $=6.46, \mathrm{df}=1, P<.05$ ). A greater proportion of beetles than expected moved to patches with edges unlike those in which they were previously captured. This was primarily due to seven beetles that left patches with tomato edges, none of which moved to patches with tomato edges. In contrast, for $A$. vittatum the presence or absence of tomato edges did not influence whether moving beetles occupied patches with or without tomatoes $\left(\chi^{2}=2.85\right.$, $\left.\mathrm{df}=1, P>.05\right)$. Similarly, the fertilization status of a patch did not influence whether moving beetles moved to fertilized or unfertilized patches $\left(A\right.$. vittatum, $\chi^{2}=2.50, \mathrm{df}=1, P>.05 ; D$. undecimpunctata, $\chi^{2}=1.75$, $\mathrm{df}=1, P>.05$ ).

Flight-behavior experiments. - In the four larger patches where flight behavior was studied, tomato edges significantly decreased the number of leaves per plant (Fig. 7). Fertilization, however, had a somewhat different effect on plant size than in the smaller patches used to examine beetle densities (Fig. 7). Plants in fertilized patches had fewer leaves than plants in unfertilized patches (Fig. 7). (Although not measured, leaves were considerably smaller in the unfertilized patches [W. S. Lawrence, personal observation].) Plant height, however, was significantly greater in fertilized patches than in unfertilized patches (Fig. 7).

The average number of $A$. vittatum flights per hour 
TABLE 4. Residency within patches, as measured by the percentage of beetles released in a patch that were subsequently recaptured in the same patch. Squash patches (S) with tomato edges and fertilization treatments are denoted $T$ and $F$, respectively.

\begin{tabular}{|c|c|c|}
\hline \multirow[b]{2}{*}{ Patch type } & \multicolumn{2}{|c|}{ Percent recaptures } \\
\hline & $\begin{array}{l}\text { A. vittatum } \\
(N=49)\end{array}$ & $\begin{array}{c}D . \\
\text { undecimpunctata } \\
\text { howardi } \\
(N=38)\end{array}$ \\
\hline$S$ & 11.0 & 10.5 \\
\hline$S / F$ & 16.8 & 31.2 \\
\hline $\mathbf{S} / \mathbf{T}$ & 0 & 0 \\
\hline $\mathrm{S} / \mathrm{T} / \mathrm{F}$ & 18.2 & 11.6 \\
\hline
\end{tabular}

per 50 beetles was not significantly influenced by either tomato edge $(F=0.093 \mathrm{df}=1,9, P>.05)$ or fertilization $(F=0.01$, df $=1,9, P>.05)$. Similarly, $D$. undecimpunctata flight frequency was not influenced by either tomato edge $(F=0.10, \mathrm{df}=1,9, P>.05)$ or fertilization treatment $(F=0.17, \mathrm{df}=1,9, P>.05)$. There were, however, highly significant differences in flight frequency between the two species $(F=38.22$, df $=1,22, P<.0001)$. D. undecimpunctata flew an average of $5.01 \pm 0.63$ times per hour per 50 beetles while $A$. vittatum flew only $0.73 \pm 0.19$ times per hour per 50 beetles, a nearly seven-fold difference.

The mean distance moved during a single flight by D. undecimpunctata $(2.24 \pm 0.14 \mathrm{~m})$ and $A$. vittatum $(2.06 \pm 0.29 \mathrm{~m})$ did not differ significantly $(F=1.96$, $\mathrm{df}=1,286, P>.05)$. Flight length was not significantly influenced by either the presence of tomato edges $(D$. undecimpunctata: $F=0.54$, df $=1,286, P>.05 ; A$. vittatum: $F=1.66, \mathrm{df}=1,36, P>.05$ ) or fertilization (D. undecimpunctata: $F=1.13$, df $=1,286, P>.05$; A. vittatum: $F=1.59$, $\mathrm{df}=1,36, P>.05$ ).

We also examined the proportion of flights beginning on squash plants that resulted in emigration from the host plant patch (flying out of the study area, landing on tomato, grass, or other non-host vegetation outside of the squash plant patch) (Table 5). This was accomplished using log-linear models for $D$. undecimpunctata (the data are too few for $A$. vittatum). Initial three-way models examining the role of tomatoes and fertilization on the proportion of beetles emigrating revealed a significant interaction $\left(\chi^{2}=9.02, \mathrm{df}=3, P<.05\right)$ and thus necessitated the use of separate two-way tables (Sokal and Rohlf 1981).
(3)
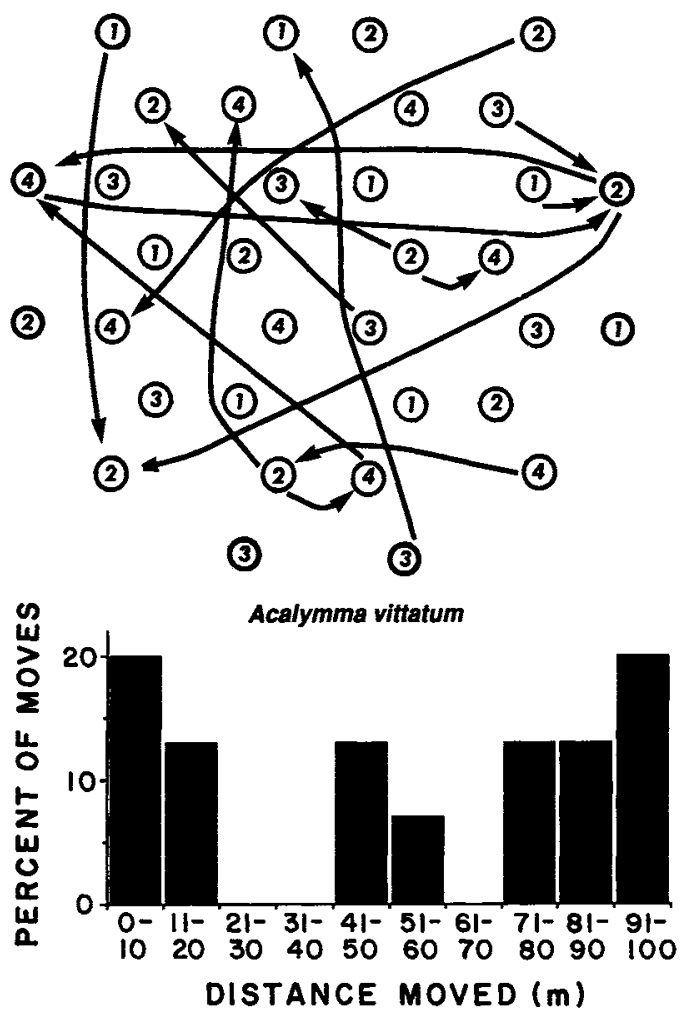

(3) (3)
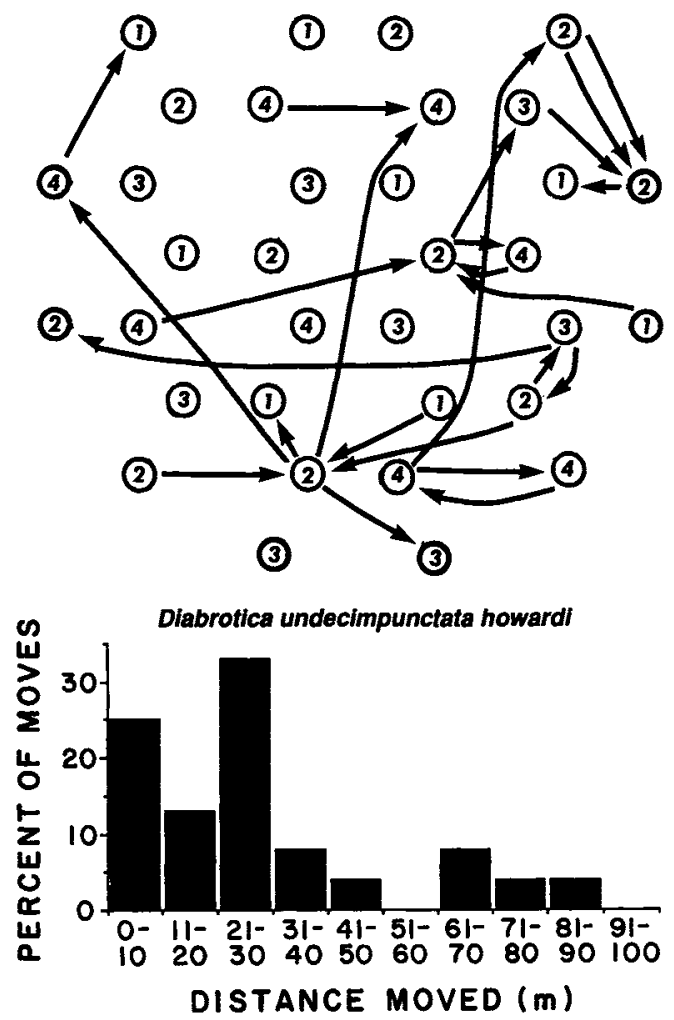

FIG. 6. Map of between-patch moves of Acalymma vittatum and Diabrotica undecimpunctata howardi and the distances moved. Arrows represent moves from initial location to subsequent point of recapture. The numbers on map refer to the four treatments as in Fig. 1. The number of between-patch moves where point of origin and recapture were known were 14 for $A$. vittatum and 24 for $D$. undecimpunctata howardi. Frequency distributions (percent) of the distances moved are also presented for each species. 

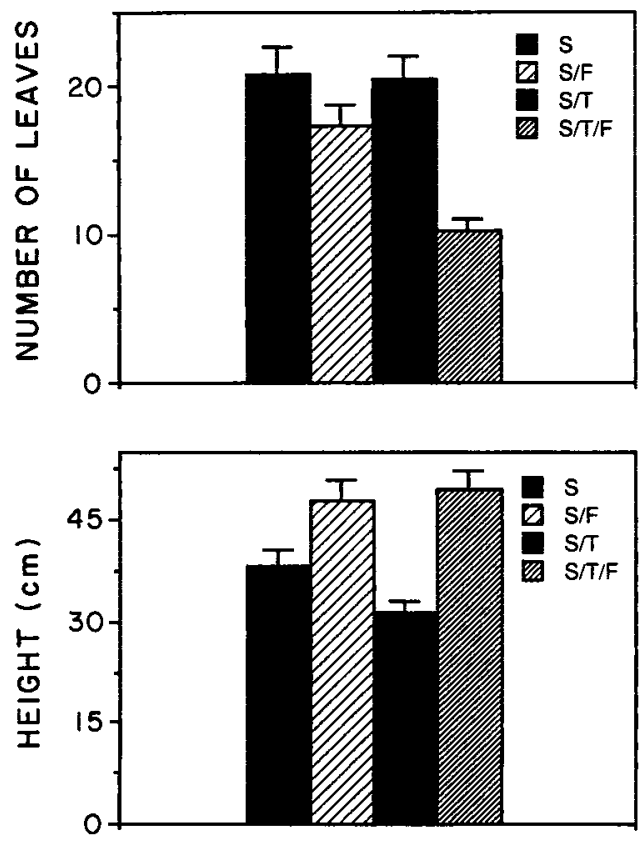

PATCH TYPE

FIG. 7. The mean number of leaves and height per plant and their standard errors are shown for the large experimental squash patches that were either without tomato edges or fertilizer (S), without tomato edges, but fertilized (S/F), with tomato edges but without fertilizer $(\mathrm{S} / \mathrm{T})$, or with tomato edges and fertilizer $(\mathrm{S} / \mathrm{T} / \mathrm{F})$. The number of leaves per plant was significantly affected by the presence of tomatoes $(F=6.61$, $\mathrm{df}=1,74, P<.01)$, fertilizer $(F=22.25, \mathrm{df}=1,74, P<.001)$ and the interaction of the two $(F=5.58, \mathrm{df}=1,74, P<.05)$. Plant height was affected only by fertilization $(F=30.42$, df $=1,74, P<.001)$.

Fertilization did not affect emigration rates either when tomatoes were present $\left(\chi^{2}=2.68, \mathrm{df}=1, P>\right.$ $.05)$ or absent $\left(\chi^{2}=0.76, \mathrm{df}=1, P>.05\right)$. Similarly, when patches were fertilized tomatoes did not affect emigration $\left(\chi^{2}=0.1, \mathrm{df}=1, P>.05\right)$, but, in contrast, when patches were unfertilized, tomatoes significantly affected emigration $\left(\chi^{2}=8.30, \mathrm{df}=1, P<.01\right)$. Beetles were more likely to leave unfertilized patches when tomatoes were present than when they were absent. Emigrating D. undecimpunctata landed on tomato plants significantly more frequently when patches were fertilized than when they were unfertilized $\left(\chi^{2}=5.85\right.$, $\mathrm{df}=1, P<.05$ ).

This increased emigration by $D$. undecimpunctata from unfertilized patches with tomato edges may be reduced by beetles returning to the patch from surrounding tomato plants. Of 12 beetles observed to fly from tomato edge plants, 11 flew back into the patch while only 1 flew away from the patch, landing on grass.

\section{DisCUSSION}

\section{Patterns of beetle abundance}

Both $A$. vittatum and $D$. undecimpunctata abundances per plant were decreased by the presence of
TABLE 5. Number of D. undecimpunctata howardi moving from squash plants to different locations as a function of treatment. Treatment abbreviations are the same as in Table 3 .

\begin{tabular}{lccccc}
\hline \hline & & & $\begin{array}{c}\text { Other } \\
\text { non- } \\
\text { hosts }\end{array}$ & $\begin{array}{c}\text { Total } \\
\text { non- } \\
\text { hosts }\end{array}$ & $\begin{array}{c}\text { Percent } \\
\text { emigra- } \\
\text { tion }\end{array}$ \\
\hline S & 59 & - & 15 & 15 & 20.3 \\
S/F & 41 & - & 15 & 15 & 26.8 \\
S/T & 34 & 15 & 11 & 26 & 43.3 \\
S/T/F & 23 & 1 & 8 & 9 & 25.8 \\
\hline
\end{tabular}

tomatoes surrounding patches of their host plant (Fig. $2 \mathrm{~A}$ and $2 \mathrm{~B}$ ). These results agree with those from the majority of other studies, which report a decrease in herbivore densities in patches with non-host plants present (see review by Risch et al. 1983). The pattern of greater densities of both $A$. vittatum and $D$. undecimpunctata in patches without tomato edges agrees with results from a related study of these two herbivore species (Bach 1988b). In addition, one of the mechanisms responsible for generating these patterns, a negative influence of non-host plants on herbivore host location and tenure time, is also similar to those documented by other workers (Tahvanainen and Root 1972, Rausher 1981, Kareiva 1985).

The similar patterns of abundance exhibited by $A$. vittatum and $D$. undecimpunctata (as a function of tomato edges) do not appear to result from responses to the same properties of the host plant patches. When plant size and correlated plant attributes were controlled for by determining densities on a per-leaf basis, the densities of $A$. vittatum were still significantly influenced by tomato edge plants. In contrast, densities of $D$. undecimpunctata were not affected by tomato plants when plant size was controlled for. From these results it appears tomato plants can affect herbivore densities in at least two important ways: (1) tomatoes can have a direct influence on the herbivores, an effect that is not mediated by any change in host plant size; (2) tomatoes can have an indirect effect on herbivores by influencing the size or other correlated attributes of nearby host plants. Of these two effects, $A$. vittatum was influenced by the direct presence of tomatoes. On the other hand, tomatoes influenced $D$. undecimpunctata densities indirectly through their effect on host plant size or quality.

It was interesting that densities of $A$. vittatum were not influenced by fertilization, but $D$. undecimpunctata densities were significantly higher in fertilized than in unfertilized patches. The response of $D$. undecimpunctata to fertilization (and lack of response by $A$. vittatum) is consistent with $D$. undecimpunctata's response to changes in host-plant size caused by tomatoes (and lack of response by $A$. vittatum). It appears $D$. undecimpunctata is more sensitive to host-plant characteristics than is $A$. vittatum, at least as measured by population densities. 
If the only effect of fertilizer was to increase plant size (an assertion only partially supported by the plant data), then it would follow that correcting for plant size by determining beetle densities on a per-leaf basis, should remove any effects of fertilization detected on a per-plant basis. For $D$. undecimpunctata this was not the case, indicating that fertilization may influence plant quality in other ways that $D$. undecimpunctata but not A. vittatum, respond to. Fertilization is well known to influence plant foliage quality (Mattson 1980). These changes however, are often complex, involving both changes potentially beneficial to the herbivore, such as increased nitrogen (van den Driessche and Webber 1975), and potentially detrimental to the herbivore, such as increased secondary compounds (Gershenzon 1984). Herbivores are also known to respond to fertilization-induced differences in plant foliage (Heidorn and Joern 1987, Strauss 1987). Interestingly, Strauss (1987) found that leaf-chewing insects had the most variable response to fertilization and that chrysomelid beetle abundance decreased significantly in fertilized patches of Artemisia ludoviciana.

Results presented here can be directly compared to those of Bach (1988b), who looked at the effects of both patch size and non-host-plant edges on densities of $A$. vittatum and $D$. undecimpunctata. Bach (1988b) found that $A$. vittatum densities were significantly affected by patch size (which varied from 4 to 64 plants), whereas D. undecimpunctata densities were not affected by patch size. This pattern is consistent with the lack of an effect of tomatoes per se on D. undecimpunctata population densities reported in this study. Since host plant size varies minimally with patch size, but the proximity of tomato neighbors varies substantially with patch size, it follows that $D$. undecimpunctata would be less affected by patch size than would $A$. vittatum. Population density patterns reported in Bach (1988b) also showed that both $A$. vittatum and $D$. undecimpunctata responded more strongly to the indirect changes in host-plant size or quality caused by non-host neighbors than to the direct presence of tomato neighbors per se. However, other analyses (Bach 1988b) showed that A. vittatum also responded to the direct presence of nonhost neighbors, which agrees with results from this study.

\section{Movement behavior}

Our results on movement suggest a mechanism by which the distribution patterns of $A$. vittatum and $D$. undecimpunctata observed in the field can be explained. Both species preferentially colonized patches without tomato edges, but, as indicated above, $A$. vittatum was probably responding to tomatoes per se. In contrast, $D$. undecimpunctata was probably responding to differences in plant size, or some aspect of plant quality correlated with plant size, resulting from the presence or absence of tomatoes. Moreover, colonists represented a different proportion of the beetles of each species that were captured and these differences were, for D. undecimpunctata, treatment dependent. D. undecimpunctata colonists represented a higher proportion of captures in patches with tomato edges and in patches without fertilization. This implies that $D$. undecimpunctata were either remaining in, or moving to, patches without tomato edges and with fertilization while $A$. vittatum were not.

Results substantiate the assertion that the two species exhibit different patterns of residency and interpatch movement. Neither tomatoes nor fertilization influenced $A$. vittatum residency or interpatch movement. In contrast, $D$. undecimpunctata remained longer in patches without tomato edges and with fertilization. D. undecimpunctata also moved from patches with tomato edges to patches without tomato edges significantly more frequently than expected. These differences in movement behavior between $A$. vittatum and D. undecimpunctata may help explain their different response to patch size, as reported in Bach (1988a). The increase in $D$. undecimpunctata density with increasing patch size may result from the effect of tomato edges on residency and interpatch movement by $D$. undecimpunctata. Since tomato edges decrease residency, smaller patches with their greater perimeter: area ratios should experience reduced residency and greater rates of emigration.

The results obtained from the flight experiments correspond closely to those from the population study. The finding that $D$. undecimpunctata flew considerably more frequently than $A$. vittatum fits qualitatively with population-level results indicating that $D$. undecimpunctata moved more between patches and exhibited greater post-colonization movement than $\operatorname{did} A$. vittatum. The flight experiments suggest that neither the great distances moved between patches by $A$. vittatum, nor the more frequent interpatch movement of $D$. undecimpunctata observed in the population-level study, resulted from differences between the species in average flight length. The emigration rates of $D$. undecimpunctata were significantly higher from unfertilized patches with tomato edges than from the other treatments, and A. vittatum showed constant levels of emigration irrespective of treatment, findings also consistent with results from the population study.

The finding that more beetles land on tomato edge plants when the patches were unfertilized than when they are fertilized suggests a mechanism that may be an important influence on beetle emigration. Flying beetles may more frequently contact the surrounding vegetation when the surrounding vegetation is taller than the host vegetation, as is the case here where tomato plants are the same size in all treatments but squash plants are taller in the fertilized treatments (Fig. 7). A similar finding is also reported by Bach (1988b). In this study, however, significantly more of the beetles flying from tomato plants moved back into the squash patch as compared to away from it. This suggests that 
the high levels of emigration of $D$. undecimpunctata from unfertilized patches surrounded by tomatoes in the population studies occurred in spite of possible trapping of potential emigrants by tomato plants.

Taken together, the results on beetle flight indicate that patterns of $D$. undecimpunctata and $A$. vittatum population dynamics result at least in part from different propensities to respond to local conditions by flight. Caution, however, should be taken in making direct comparisons between the flight studies and the population studies, since beetle flight behavior may differ as a function of patch size. It should also be noted that, although the flight-behavior experiment results are consistent with results from the population study, the experiment was replicated only in time, and care should be taken in interpreting the results.

The results on colonization strongly indicate that $A$. vittatum shows initial discrimination between patches on the basis of edge treatment, but that abundance patterns are not influenced by subsequent movement. While $D$. undecimpunctata also shows initial preferences, these patterns are significantly modified by the subsequent patterns of residence and movement. Thus, it appears $A$. vittatum responds primarily to the physical presence of tomatoes and exhibits limited local movement. Most host-plant patch selection by $A$. vittatum appears to occur during initial colonization. In contrast, $D$. undecimpunctata is primarily responsive to plant size and/or quality as affected by both fertilizer and tomato plant patch edges. Moreover, high levels of local movement allow $D$. undecimpunctata to redistribute themselves after a relatively unselective initial colonization and to occupy patches with favorable conditions. This strategy may allow $D$. undecimpunctata to adjust more rapidly to spatially and temporally variable environments and may be in part a consequence of its evolutionary history as a feeding generalist.

\section{Conclusions}

Results from this study showed somewhat different patterns of abundance of two closely related herbivore species in the same experimental gardens. Numerous other studies also report differences in herbivore response to various aspects of "resource concentration" (Root 1973), including patch size, plant density, and plant diversity (see reviews by Kareiva 1983 and Stanton 1983). In fact, the search for generalizations regarding herbivore response to plant spatial pattern has been relatively unsuccessful. This study, however, emphasizes that differences in distribution patterns of herbivores in the same experimental patches can be understood in the context of differences in herbivore movement behavior.

This study emphasizes the importance of mechanistic experiments in explaining distribution patterns. Although movement was shown to be an important factor, the role of other differences in herbivore behavior in affecting herbivore response to plant spatial pattern needs to be examined. Only by using such mechanistic and comparative approaches will we be able to develop a predictive theory of effects of plant spatial pattern on insect herbivore abundance.

\section{ACKNOWLEDGMENTS}

We thank the Matthaei Botanical Gardens (University of Michigan) for providing field sites and greenhouse space. Lew Birmelin helped maintain the field plots and Jim Dickenson helped grow plants in the greenhouse. We also thank Paula Bergstrom, Martha Bohm, Christine Martinez, and Mike O'Neil for their help with field work and data entry. This research was supported in part by a grant to C. E. Bach from the University of Michigan, Office of the Vice-President for Research.

\section{Literature Cited}

Bach, C. E. 1980a. Effects of plant density and diversity on the population dynamics of a specialist herbivore, the striped cucumber beetle, Acalymma vittatum (Fab.). Ecology 61: $1515-1530$.

151 $1980 \mathrm{~b}$. Effects of plant diversity and time of colonization on a herbivore-plant interaction. Oecologia (Berlin) 44:319-326

- 1988a. Effects of host plant patch size on herbivore density: patterns. Ecology 69:1090-1102.

. $1988 \mathrm{~b}$. Effects of host plant patch size on herbivore density: underlying mechanisms. Ecology 69:1103-1117.

Campbell, W. V., and D. A. Emery. 1967. Some environmental factors affecting feeding, oviposition, and survival of the southern corn rootworm. Journal of Economic Entomology 60:1675-1678.

Gershenzon, J. 1984. Changes in the levels of plant metabolites under water and nutrient stress. Pages 273-320 in B. N. Timmerman, C. Steelink, and F. A. Loewus, editors. Phytochemical adaptations to stress. Recent advances in phytochemistry. Volume 18. Plenum, New York, New York, USA.

Heidorn, T. J., and A. Joern. 1987. Feeding preference and spatial distribution of grasshoppers (Acrididae) in response to nitrogen fertilization of Calamovilfa longifolia. Functional Ecology 1:369-375.

Houser, J. S., and W. V. Balduf. 1925. The striped cucumber beetle. Bulletin of the Ohio Agricultural Experiment Station 388.

Kareiva, P. 1983. Influence of vegetation texture on herbivore populations: resource concentration and herbivore movement. Pages 259-289 in R. F. Denno and M. S. McClure, editors. Variable plants and herbivores in natural and managed systems. Academic Press, New York, New York, USA.

1985. Finding and losing host plants by Phyllotreta: patch size and surrounding habitat. Ecology 66:1809-1816.

Lawrence, W. S. 1988. Movement ecology of the red milkweed beetle in relation to population size and structure. Journal of Animal Ecology 57:21-35.

Mattson, W. J. 1980. Herbivory in relation to plant nitrogen content. Annual Review of Ecology and Systematics 11: 119-161.

Rausher, M. D. 1979. Larval habitat suitability and oviposition preference in three related butterflies. Ecology 60 : 503-511.

- 1980. Host abundance, juvenile survival, and oviposition preference in Battus philenor. Evolution 34:342355.

- 1981. The effect of native vegetation on the susceptibility of Aristolochia reticulata (Aristolochiaceae) to herbivore attack. Ecology 62:1325-1340. 
Risch, S. J., M. Altieri, and D. Andow. 1983. Agroecosystem diversity and pest control: data, tentative conclusions, and new research directions. Environmental Entomology 12: 625-629.

Root, R. B. 1973. Organization of a plant-arthropod association in simple and diverse habitats: the fauna of collards (Brassica oleracea). Ecological Monographs 43:95124.

Sokal, R. R., and F. J. Rohlf. 1981. Biometry. W. H. Freeman, San Francisco, California, USA.

Stanton, M. L. 1983. Spatial patterns in the plant community and their effect upon insect search. Pages 125-155 in $\mathrm{S}$. Ahmad, editor. Herbivorous insects: host seeking behavior and mechanisms. Academic Press, New York, New York, USA.
Strauss, S. Y. 1987. Direct and indirect effects of host-plant fertilization on an insect community. Ecology 68:16701678.

Tahvanainen, J. O., and R. B. Root. 1972. The influence of vegetational diversity on the population ecology of a specialized herbivore, Phyllotreta cruciferae (Coleoptera: Chrysomelidae). Oecologia (Berlin) 10:321-346.

Turchin, P. 1987. The role of aggregation in the response of Mexican bean beetles to host-plant density. Oecologia (Berlin) 71:577-582.

van den Driessche, R., and J. E. Webber. 1975. Variation in total and soluble nitrogen concentrations in response to fertilization of Douglas-fir. Forest Science 23:134-142.

Wilkinson, L. 1988. Systat: the system for statistics. Systat Inc., Evanston, Illinois, USA. 